\title{
O uso do picolinato de cromo como coadjuvante no tratamento da diabetes mellitus
}

\author{
Antônio Felipe Corrêa Marangon ${ }^{1}$ \\ Luis Gabriel de Melo Fernandes ${ }^{2}$
}

RESUMO - O cromo é elemento essencial requerido para o metabolismo normal de carboidratos e lipídeos. A deficiência de cromo em humanos e outros mamíferos tem resultado em sintomas comparado àqueles associados ao início de diabetes, como elevação da glicose sangüínea, insulina, colesterol e triglicerídeos, e diminuição das lipoproteínas de alta densidade (HDL). A resposta ao cromo está relacionada ao grau de intolerância à glicose. Tem sido demonstrado que o cromo é efetivo no tratamento dos vários tipos de diabetes e é considerado um dos nutrientes menos tóxicos.

Palavras-chave: cromo, diabetes, intolerância à glicose.

\section{The use of the picolinato of chromium as supporting in the treatment of diabetes mellitus}

\begin{abstract}
The chromium is an essential element required for the normal metabolism of lipids and carbohidrates. The chromium deficiency in human beings and other mammals has resulted in symptoms comparative those associates to the beginning of diabetes, as rise of the glucose, insulin, cholesterol and triglycerides, and reduction of lipoproteins of high density (HDL). The reply to chromium it is related to the degree of intolerance to the glucose and has been demonstrated that it is effective in the treatment of the some types of diabetes and is considered one of the nutrients less toxic.
\end{abstract}

Key words: chromium, diabetes, intolerance to the glucose.

\footnotetext{
${ }^{1}$ Professor do curso de Nutrição e Fisioterapia do Centro Universitário de Brasília - UniCEUB. E-mail: felipemarangon@terra.com.br

${ }^{2}$ Graduandoem Nutrição do Centro Universitário de Brasília-UniCEUB.E-mail: lgabriel2@ terra.com.br
}

Univ. Ci. Saúde, Brasília, v. 3, n. 2, p. 253-260, jul./dez. 2005 
Desde que foi "descoberta", há aproximadamente 40 anos, a bioquímica do cromo foi vista como um enigma. Alguns componentes foram previamente propostos como a forma biologicamente ativa. A necessidade do cromo na nutrição humana foi documentada em 1977, quando uma paciente em nutrição parenteral total desenvolveu severos sintomas semelhantes aos de diabetes. Antes da suplementação de cromo, ela estava perdendo peso, acompanhado de intolerância à glicose e neuropatia, mesmo quando recebia 50 unidades de insulina exógena por dia. Quando $200 \mathrm{mg}$ de cromo na forma de cloreto de cromo foram adicionados à solução da nutrição parenteral por três semanas, os sintomas semelhantes a diabetes diminuíram, e a insulina exógena não foi mais necessária ${ }^{1}$.

O cromo, aparentemente, serve como nutriente e não como terapia e pode beneficiar aqueles que estão na faixa de deficiência. Os efeitos positivos atribuídos ao cromo surgem da interação com biomoléculas específicas ${ }^{2}$. O cromo trivalente é presente em comidas e suplementos em diversas formas. A mais popular encontrada é o picolinato de cromo ${ }^{3}$. A deficiência de cromo em humanos e outros mamíferos tem resultado em sintomas comparados àqueles associados ao início de diabetes e doença cardiovascular. Entretanto, os efeitos de sua administração não têm sido observados em todos os casos.

O picolinato de cromo é utilizado como forma de tratamento oral que auxilia a redução do peso e a alteração da composição corporal. É um composto trivalente de cromo, elemento-traço essencial cofator para insulina, e ácido picolínico, derivado do triptofano. O cromo aumenta a atividade da insulina e tem sido objeto de estudos que avaliam o metabolismo de carboidratos, proteínas e lipídeos. Os efeitos sugeridos incluem aumento da massa magra, diminuição do percentual de gordura e aumento da taxa de metabolismo basal ${ }^{4}$. Sinais de deficiência têm sido documentados em numerosas ocasiões, incluindo elevação da glicose sangüínea, insulina, colesterol e triglicerídeos e diminuição das lipoproteínas de alta densidade (HDL) ${ }^{5}$.

Enquanto o mecanismo do cromo na melhora da sensibilidade à insulina ainda está sendo determinado, um estudo feito por Bingham et al. (2000) sugere que esse elemento pode ser benéfico para pacientes com diabete tipo II pelo aumento da sensibilidade pela insulina endógena, uma vez que está associada tanto ao aumento da sua ação como ao aumento do número de seus receptores ${ }^{6}$.

\footnotetext{
${ }^{1}$ ANDERSON, 1998; VINCENT, 1999.

${ }^{2}$ VINCENT, 1999.

${ }^{3}$ LAMSON\& PLAZA, 2002.

${ }^{4}$ PITTLER etal., 2003; PITTLER \& ERNST, 2004.

${ }^{5}$ ANDERSON, 1998.

${ }^{6}$ MORRIS etal., 2000.
} 
No entanto, a suplementação dietética de cromo não está associada a níveis de concentração de glicose em indivíduos não-diabéticos ${ }^{7}$.

A resposta ao cromo está relacionada ao grau de intolerância à glicose. Um estudo confirmou que a redução da área na curva de tolerância à glicose está associada ao aumento na ligação da insulina, aumentando o número de receptores, aliviando os sintomas da hipoglicemia, incluindo visão borrada, sudorese, sonolência, etc. O mecanismo pelo qual a suplementação de cromo leva à redução da glicose sangüínea em indivíduos com elevadas taxas de glicemia e aumenta em pessoas com hipoglicemia é uma das funções do cromo na regulação ou na potencialização da ação da insulina. A melhora na eficiência da insulina em indivíduos com elevadas taxas de glicemia leva à absorção de glicose mais eficiente. Em indivíduos com hipoglicemia, a suplementação de cromo também conduz à normalização da função da insulina e à melhora na eficiência da insulina no retorno de concentrações normais mais rapidamente em resposta à mudança na concentração sangüínea de glicose. No entanto, indivíduos com boa tolerância à glicose que não necessitam de cromo adicional não respondem à suplementação do cromo. Indivíduos que consomem a quantidade adequada de cromo também não respondem à adição de cromo ${ }^{8}$.

A suplementação de cromo tem sido relatada com efeitos positivos no perfil lipídico. Pacientes com resistência à insulina freqüentemente sofrem de dislipidemias. A suplementação de cromo pode ter efeito em ambas as situações, já que interfere na ação da insulina. Além desse efeito, a potencialização da ação da insulina estimula a absorção de glicose e aminoácidos, o que resulta em efeito anabólico, com conseqüente aumento de massa magra e diminuição de massa gorda ${ }^{9}$. No entanto, Vincent (2003) observa que a suplementação com picolinato de cromo associada a um programa de treinamento físico não facilita a perda de massa gorda. Embora o picolinato de cromo não promova benefícios no que diz respeito a mudanças na composição corporal em humanos, existe limitado número de estudos que indicam suplementos de cromo não promoverem ganho de músculo e perda de gordura, como determinado pelos métodos de avaliação da composição corporal.

Existem estresses que alteram o estado do cromo, que são: absorção de glicose, dietas ricas em açúcares simples, gravidez, lactação, infecção, exercício agudo e crônico e trauma físico. A perda urinária de cromo pode ser utilizada como método para mensurar a mobilização, já que não é reabsorvido pelos rins, e sim excretado na urina. $\mathrm{O}$ nível de estresse é proporcional à perda de cromo na urina.

${ }^{7}$ ALTHUIS etal., 2002.

${ }^{8}$ ANDERSON, 1998.

${ }^{9}$ PASMAN, 1997.

Univ. Ci. Saúde, Brasília, v. 3, n. 2, p. 253-260, jul./dez. 2005 
Por exemplo, exercício aeróbico de intensidade moderada (50\% do consumo máximo de oxigênio) não aumenta significantemente a perda de cromo na urina, enquanto exercícios a $90 \%$ do consumo máximo de oxigênio aumentam. Há correlação direta entre o aumento do cortisol em resposta ao estresse e a perda de cromo na urina. Portanto, aumenta a perda urinária de cromo em casos de administração de corticoesteróides ${ }^{10}$.

A deficiência de cromo pode resultar em hipoglicemia ou sintomas de diabetes. $\mathrm{O}$ tratamento do diabetes tipo $2 \mathrm{com}$ cromo leva à melhora na glicose sérica $\mathrm{e}$ insulina. O controle da glicose também melhora o diabetes tipo 1. A suplementação de cromo reduz a resistência à insulina no diabetes gestacional. O cromo é efetivo para reverter o diabetes causado pela terapia com glicocorticóides. Os efeitos do cromo na homeostasia da glicemia são acompanhados por aumento na ativação de receptores de insulina. Com isso, tem sido demonstrado que o cromo é efetivo no tratamento dos tipos de diabetes, incluindo o tipo 1 e 2 , o gestacional e o diabetes induzido por corticoesteróides ${ }^{11}$.

\section{Modo de ação do cromo}

O cromo aumenta a ligação da insulina com as células pelo aumento no número de receptores. O receptor da insulina está presente em todas as células, porém em concentrações que variam de, aproximadamente, 40 receptores por célula por eritrócitos até mais de 200.000 receptores nos adipócitos e hepatócitos. O receptor de insulina é composto por duas subunidades alfa extracelular de peso molecular de 135,000 que contém um sítio de ligação da insulina e duas subunidades beta-transmembrana com peso molecular de 95,000. Quando ocorre a ligação na subunidade alfa do receptor da insulina, a fosforilação específica da subunidade beta ocorre por uma cascata de reações de fosforilação intermoleculares. O cromo parece, como a insulina, afetar as reações de fosforilação-desfosforilação de proteínas. A enzima responsável pela fosforilação que leva ao aumento da sensibilidade à insulina no receptor tirosina cinase é ativada pelo cromo. $\mathrm{O}$ baixo peso molecular do cromo na ligação não afeta a atividade da proteína cinase em adipócitos de ratos na ausência de insulina. Em contrapartida, estimula a atividade da cinase na presença da insulina. A remoção do cromo de baixo peso molecular provoca resultados na perda da potencialização da atividade da cinase. O cromo também inibe a fosfotirosina fosfatase, presente em ratos, que é homóloga à tirosina fosfatase, que inativa o receptor da insulina. A ativação pelo cromo da atividade cinase do receptor da insulina e a inibição do receptor tirosina fosfatase da insulina

${ }^{10}$ RAVINA etal., 1999.

${ }^{11}$ LAMSON\& PLAZA, 2002. 
podem levar ao aumento da fosforilação do receptor da insulina, que está associado à melhora da sensibilidade à insulina. No entanto, a inibição específica da atividade do receptor da insulina fosfotirosina fosfatase necessita de mais estudos ${ }^{12}$.

\section{Ingestão adequada (AI)}

A ingestão adequada do cromo para crianças até 6 meses é de 10-40 mg por dia; para crianças de 5 meses a 1 ano, é de 20-60 mg; para crianças de 1 a 3 anos, de 20-80 mg. Na faixa etária de 4 a 6 anos, é de 30-120 mg e, por fim, de 7 anos em diante, é de 50-200 mg por dia. No caso de crianças até 6 meses, a ingestão adequada é baseada na quantidade obtida no leite materno, cuja quantidade de cromo é por volta de $0,18 \mathrm{mg} / \mathrm{litro}$. A American Academy of Pediatrics recomenda que o leite materno seja a única fonte de nutrientes para crianças até 6 meses de idade. Baseado nos valores de referência atuais para crianças, seria necessário o consumo de 55,6 litros de leite materno por dia para que se obtenha a ingestão mínima adequada de $10 \mathrm{mg}$. Embora o cromo presente no leite materno parece ter maior biodisponibilidade que outras fontes, mais estudos são necessários ${ }^{13}$.

Estar na faixa da ingestão adequada de cromo diariamente é importante, porém existem fatores que interferem na absorção, como, por exemplo, elevadas quantidades de açúcares simples influem negativamente na absorção do cromo, além de aumentar a perda urinária. A ingestão de 30 a $40 \mathrm{mg}$ de cromo por dia pode ser suficiente se, na dieta, o consumo de açúcares simples for baixo, e o de frutas frescas e vegetais for alto ${ }^{14}$.

\section{Absorção e vias de excreção}

Assim como outros minerais, as formas orgânica e inorgânica do cromo são absorvidas de maneira diferente. $\mathrm{O}$ cromo orgânico é prontamente absorvido, porém é rapidamente eliminado ${ }^{15}$.

Nas últimas três décadas, as evidências têm demonstrado que tanto os fatores endógenos quanto os exógenos alteram significativamente a absorção e a biodisponibilidade do cromo. A absorção do cromo trivalente depende do tipo de cromo ingerido, da interação entre minerais e do efeito de vitaminas, proteínas, drogas e outros fatores nutricionais. Fatores dietéticos, como goma, ácido ascórbico, minerais, oxalato e aminoácidos, podem ter influência significativa na absorção do cromo.

${ }^{12}$ ANDERSON, 1998.

${ }^{13}$ ANDERSON, 1998.

${ }^{14}$ ANDERSON, 1998.

${ }^{15}$ MAHAN\&ESCOTT-STUMP, 2005.

Univ. Ci. Saúde, Brasília, v. 3, n. 2, p. 253-260, jul./dez. 2005 
A ingestão de carboidrato tem mostrado influência na excreção urinária. Dietas ricas em açúcares simples apresentam aumento na excreção urinária do cromo de 10 a 300\%, com mudanças nas taxas de absorção. O ácido ascórbico demonstra aumento da absorção ${ }^{16}$.

Existe influência dos demais minerais na absorção do cromo. Em estudos com ratos, a suplementação de zinco reduziu a absorção de cromo, enquanto a deficiência de zinco promoveu efeito oposto, aumentando os níveis de cromo. Como o ferro e o cromo são carreados pela transferrina, acredita-se que há competição entre o ferro e o cromo nos sítios de ligação da transferrina ${ }^{17}$.

Um número de aminoácidos aumenta a absorção do cromo no intestino. Foi observado que uma mistura com 20 aminoácidos dobrou a absorção. Aminoácidos, como histidina e ácido glutâmico, que formam complexos com o cromo, também mostram aumento na absorção ${ }^{18}$.

\section{Efeitos tóxicos do picolinato de cromo}

Em relação à ingestão dietética, a ingestão na qual o cromo se torna prejudicial ou tóxica é tão alta que, atualmente, pode-se apenas estimá-la ${ }^{19}$.

Estudos demonstram ausência de efeitos colaterais em participantes que ingerem picolinato de cromo. Muitos autores observam que sua manipulação é relativamente segura. Entretanto, outros estudos identificaram que existem potenciais riscos de ocorrência de danos no cromossomo humano caso o consumo seja tão elevado ${ }^{20}$. Um estudo realizado por Lamson \& Plaza (2002) apresenta que a concentração do cromo trivalente nos vários tecidos pode causar danos cromossomiais e aberrações pela ação clastogênica (mutação específica que causa rompimento em cromossomos) da ação do metal, como se observa em estudos in vitro. O picolinato de cromo parece causar efeito clastogênico pelo potencial redox do composto, que pode entrar na célula com possível geração de radicais hidróxidos.

O cromo trivalente, forma de cromo encontrado em alimentos e suplementos nutricionais, é considerado um dos nutrientes menos tóxicos. A dose de referência estabelecida pela US Environmental Protection Agency para cromo é de 350 vezes o valor limite da ingestão adequada de $200 \mathrm{mg} / \mathrm{dia}^{21}$. Contudo, para estabelecer

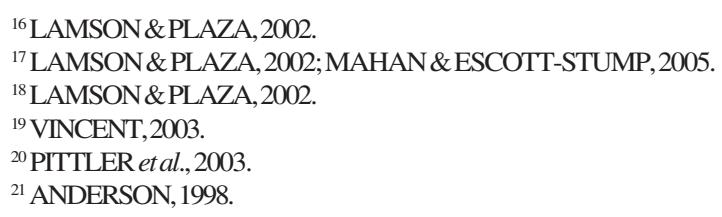


a segurança da utilização do picolinato de cromo, mais estudos em humanos são necessários ${ }^{22}$.

\section{Suplementação de cromo em situações de diabetes e intole- rância à glicose}

As taxas de glicose e insulina variam de acordo com mudanças na dieta, exercício e utilização de medicamentos ${ }^{23}$. Aumentos nas concentrações séricas de glicose resultam em aumento da excreção urinária de cromo. Condições que alteram o metabolismo da glicose (incluindo diabetes no início da fase adulta e exercício) alteram a excreção do cromo. Mudanças no metabolismo da glicose resultam em mudanças de controle do cromo, sugerindo associação direta entre os dois. No caso do diabetes, são encontrados baixos níveis de cromo plasmático e altos níveis de cromo excretado na urina, o que leva à deficiência dessa substância. Entretanto, isso pode ser potencialmente aliviado por suplementação $0^{24}$.

Recentemente, a suplementação de cromo (na forma de picolinato de cromo) mostra efeitos benéficos em pacientes adultos com início de diabetes ${ }^{25}$. O picolinato de cromo é apresentado com função de melhorar marcadores de controle diabético em pacientes com diabetes mellitus tipo 2 e inverter a indução diabética de corticoesteróides ${ }^{26}$.

Vincent (2003) observa que a utilização do picolinato de cromo não mostrou nenhum efeito nas concentrações de insulina ou glicose em indivíduos saudáveis. Porém, Lamson \& Plaza (2002) defendem que, mesmo em pessoas saudáveis, a suplementação de cromo pode aumentar a sensibilidade pela insulina e diminuir a concentração sérica de glicose e a produção de insulina.

\section{Conclusão}

Existem fatores que contribuem para diferentes resultados nos estudos a respeito do cromo. Nos que incluem humanos, devem ser levados em consideração os fatores genéticos, nutricionais e ambientais, como, por exemplo, o estresse, que pode interferir no metabolismo do cromo. Outro fator a ser levado em consideração é a seleção da amostra, a duração do estudo e o tipo de suplementação

\footnotetext{
${ }^{22}$ VINCENT,2003.

${ }^{23}$ ALTHUIS etal., 2002.

${ }^{24}$ MORRIS etal., 2000; VINCENT, 2003.

${ }^{25}$ VINCENT, 1999

${ }^{26}$ MORRIS etal., 2000.
}

Univ. Ci. Saúde, Brasília, v. 3, n. 2, p. 253-260, jul./dez. 2005 
de cromo. Os estudos realizados incluem amostra muito pequena para que se possam ser tiradas conclusões a respeito do efeito do cromo na intolerância à glicose ${ }^{27}$.

\section{Referências}

ALTHUIS, M. D., et al. 2002. Glucose and insulin responses to dietary chromium supplements: a meta-analysis. In: American Society for Clinical Nutrition, 76, pp. 148-155.

ANDERSON, R. A. Chromium, Glucose Intolerance and Diabetes. 1998. In: Journal of the American College of Nutrition, 17, pp. 548-555.

LAMSON, D. W. \& PLAZA, S. M. 2002. The Safety and Efficacy of High-Dose Chromium. In: Alternative Medicine Review, 7, pp. 218-235.

MAHAN, L. K. \& ESCOTT-STUMP, S 2005. Krause: Alimentos, Nutrição \& Dietoterapia. 11. ed. São Paulo: Roca, 1242 p.

MORRIS, B. W. et al. 2000. Cromium supplementations improves insulin resistence in patients with Type 2 diabetes mellitus. In: British Diabetic Association. Diabetic Medicine, 17, pp. 684-686.

PASMAN, W. J., WESTERTERP-PLANTENGA, M. S., SARIS, W. H. M. 1997. The effectiveness of long-term supplementation of carbohydrate, chromium, fibre and caffeine on weight maintenance. In: International Journal of Obesity, 21, pp. 1143-1151.

PITTLER, M. H. \& ERNST, E. 2004. Dietary supplements for body-weight reduction: a systematic review. In: American Journal of Clinical Nutrition, 79, pp. 529-536.

PITTLER, M. H., STEVINSON, C., ERNST, E. 2003. Chromium picolinate for reducing body weight: Meta-analysis of randomized trials. In: International Journal of Obesity, 27, pp. 522-529.

RAVINA, A., et al. 1999. Reversal of corticosteroid-induced diabetes mellitis with supplemental chromium. In: British Diabetic Associantion, 16, pp. 164-167.

VINCENT, J. B. 1999. Mechanisms of Chromium Action: Low-Molecular-Weight Chromium-Binding Substance. In: Journal of the American College of Nutrition, 18, pp. 6-12.

- 2003. The Potential Value and Toxicity of Chromium Picolinate as a Nutritional Supplement, Weight Loss Agent and Muscle Development Agent. In: Sports Med, 33, pp. 213-230.

${ }^{27}$ ALTHUIS etal., 2002; ANDERSON, 1998. 